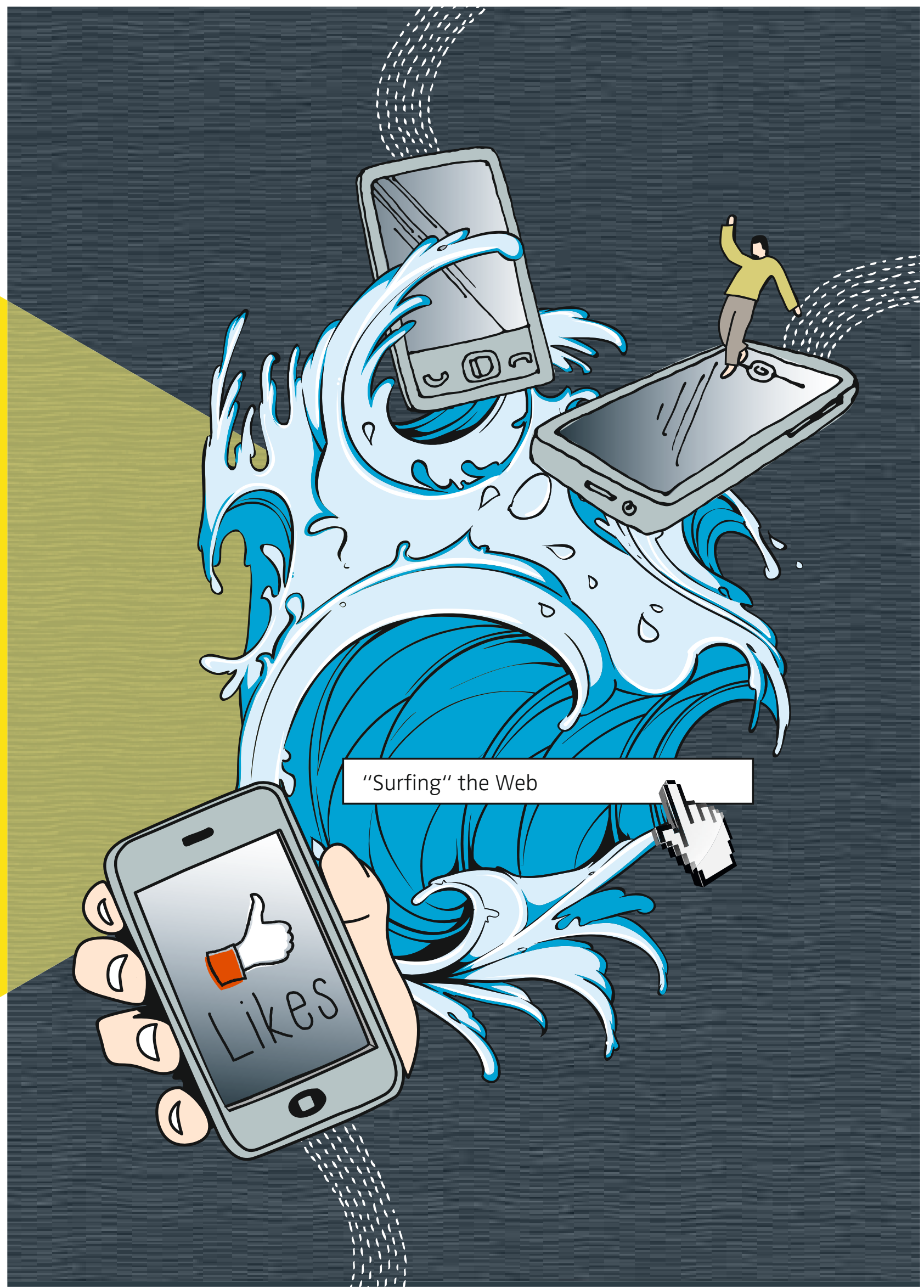

Bereitgestellt von | Vienna University Library 


\title{
Follow the Connections! Finding the Big Picture of Internet Communications
}

\author{
Axel Maireder
}

KEYWORDS

Network Analysis,

Internet Communications,

Online Discourse,

Online Communities, Twitter

THE AUTHOR

Dr. Axel Maireder,

Head of the TANEP project, Department of Communications,

University of Vienna, Austria,

axel.maireder@univie.ac.at

Contact GfK Verein:

Carolin Kaiser,

specialist for social media analysis, carolin.kaiser@gfk-verein.org

Contact GfK SE:

Christian Waldheim,

global head of social media intelligence, christian.waldheim@gfk.com

Everybody has a say /// Our media landscape is no longer populated by just the mass media and professional players. As far as market communications go, it is also increasingly evolving into an open, diverse and multilayered vista: Products and services are evaluated on ratings platforms and discussion forums. Advertising campaigns are dissected on social networks. Blogs report on the latest fashion, sports and technology trends. Consumers then continue the conversation on Facebook and Twitter. For this reason, markets can be viewed as conversations in which an online community, often a global one, passionately discusses issues related to consumption and consumer society. Companies have taken on the challenges posed by this new means of social discourse: They promote their products in "viral" ads, chat with their customers on Facebook and insert their names into Twitter conversations.

\section{Online discourse - a mother lode for market researchers}

$/ / /$ At the heart of this process is the constant monitoring and analysis of communications. In recent years, a broad market has emerged for such Web and social media monitoring. Many tools can be used to track down, store and comprehensively evaluate digital objects, things like how "buzz" develops and how "sentiments" are determined. This information can be used to develop a general evaluation of certain products or a schedule for releasing marketing material on these products. At the same time, the relevance of individual digital objects (e.g., tweets, blog posts and YouTube videos) and actors (e.g., individuals, media and organizations) frequently remains just as much of a mystery as the high-level networking and 
FIGURE 1:

\section{Central segment of the hyperlink document network for the discourse on HTC First and Facebook Home}

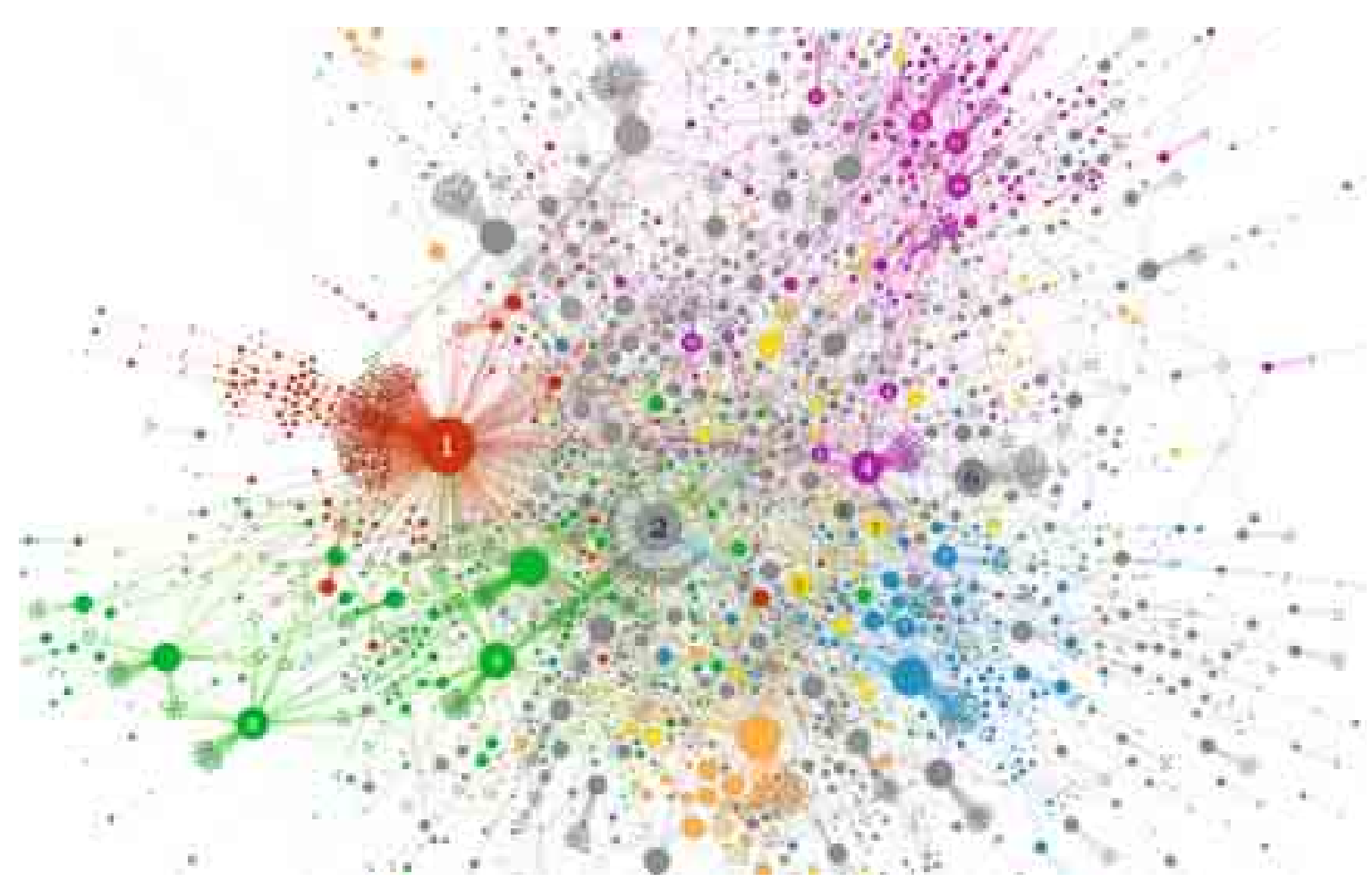

- Red: Comments contain a reference to Google Play store

- Yellow: Discussion about usability

- Pink: Discussion about data security

- Blue: Information about weak sales

- Orange: Information about canceled sales launch in Europe

- Green: Hacker community

In the period from April 4 to June 3, 2013. The home pages of Facebook and HTC were removed from the network. A total of 5,393 nodes, 8,028 edges; colors based on clusters.

dynamics of the discussion do. It is the dynamics of these networks that most significantly contribute to the way that opinions are shaped on the Internet and determine whether videos go "viral" and discussions become "flame wars." As part of the TANEP (Towards an Analytics of Networked Publics) project, the GfK Verein is funding research on methods that can bring these dynamics to visual life and, as a result, reflect the essence of the Internet as a network.
What hyperlink networks reveal: the structure of discourse /// "The link is the heart of the Web," says Tim Berners-Lee, the father of the World Wide Web: The linking of documents using hyperlinks represented the first step in its evolution and even now remains central to its existence. Writers add hyperlinks as a way of referencing particular objects. Today, this process involves linking and embedding texts, images and videos in online social networks like Facebook 
$\{$ Box 1$\}$

\section{MACRO DISCOURSE ANALYSIS: INTRODUCTION OF THE HTC FIRST CELL PHONE}

During a major press event held on April 4, 2013, HTC and Facebook announced the first cell phone that runs the Facebook operating system: the HTC First, which features a version of Android called Facebook Home. The phone went on sale in the United States on April 12. But it went nowhere. After a month of lethargic sales, AT\&T dropped the device from its product line. In Europe, the sales launch was repeatedly put off. What happened? An analysis of the public discussion about the cell phone offered a few starting points: From the beginning of April until mid-June, a total of 5,339 documents were identified on websites with the keywords "HTC First" and "Facebook Home" and were analyzed for the ways they were paired with hyperlinks (see Figure 1). This underscored the relevance of the largely negative user comments in the Google Play Store [1] to which many blog posts and commentators referred (the red section of the graphic).

Through the employment of cluster analysis, a process that can be used to identify very strongly linked parts of a network, it was also possible to track diverse thematic and discussion threads: The integration of Facebook into the operating system was frequently criticized from a usability perspective (the yellow seg- ments of the illustration), and data-security concerns were expressed as well (pink). Technical blogs like Techcrunch [2] summarized these opinions, which seemed to be confirmed by issues related to weak sales (blue) and the delay in the sales launch in Europe (orange). The device's actual technical specifications were only discussed in passing. It turns out that linking its cell phone to Facebook software backfired for HTC. Contributing to this was also the hacker community, which quickly swung into action, modifying Facebook Home within just a few days and enabling it to work on other cell phones (green).

Central sites for the discourse could be identified as well. In addition to the Google Play [1] store, the technology portals Techcrunch [2], The Verge [3], Cnet [4] and Wired [5] as well as business media like Bloomberg [6] and Business Insider [7] played a role here. One particularly interesting analysis tracked discussions on the top sites arranged by subject, showing, for instance, the XDA Developers community [8] and Modaco [9] covering the software hacks as well as the blogs GigaOM [10] and TechNet [11] along with some specific YouTube [12] videos tackling the privacy issue. 
and Twitter. They facilitate the nonlinear navigation that we know informally as "surfing." Analysis of hyperlink networks from a macro perspective makes it possible to retrace diffusion processes online. On the one hand, the reconstruction displays various subject fields and their linking. On the other hand, it facilitates the attribution of relevance to individual objects and actors: Which documents and websites played a key role in the development of particular argument patterns? How did the actors refer to one another in the process? By including additional data, particularly information taken from social media like Twitter and Facebook, the complex diffusion patterns can be reconstructed. This approach makes it possible to follow discussions about campaigns, identify key actors and platforms for media planning and map the structure of special-interest communities.

〉)

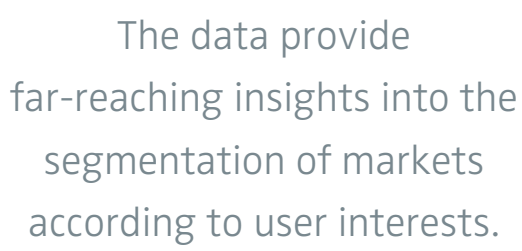

$<<$
The following example, a network analysis of the discussion about the HTC First cell phone, shows just what sort of insights can be gleaned.

Account networks: identifying interest groups /// Monitoring networking processes among actors on individual sites and objects appeals to market research for another reason as well: People regularly use the Internet to form groups according to their shared needs, problems and interests. For this reason, link-sensitive Web and social media analysis can provide deep insights into the constellations of interests among users. Account networks in social media applications reflect these shared interests and form the foundation for the dissemination of information.

Another goal of the TANEP project is to discover and analyze such communities in social media networks. This approach is not based on hyperlinks. Instead, it concentrates on the interactions among user accounts in such places as Twitter. Here, follower networks are viewed as being representatives of interest groups. Even though the reasons for "following" a certain Twitter account can be very diverse, it can be assumed that the users have an interest in the tweets posted by this account. When the macro perspective displays clusters of nodes, it can be assumed that shared interests exist. Companies, brands and products can be a part of these communities' identities and the communications within them, even though they can hardly be viewed as "brand communities" because they are not primarily organized by brands. The groupings can be interpreted by further analysis of the account descriptions or the published tweets. The data provide far-reaching insights into the segmentation of markets according to user interests. In addition, information is gained regarding the relevance of certain accounts and account groups for the diffusion of information. For instance, an analysis of the Twitter account "Red Bull X-Alps" shows how communities can be identified and interpreted. 

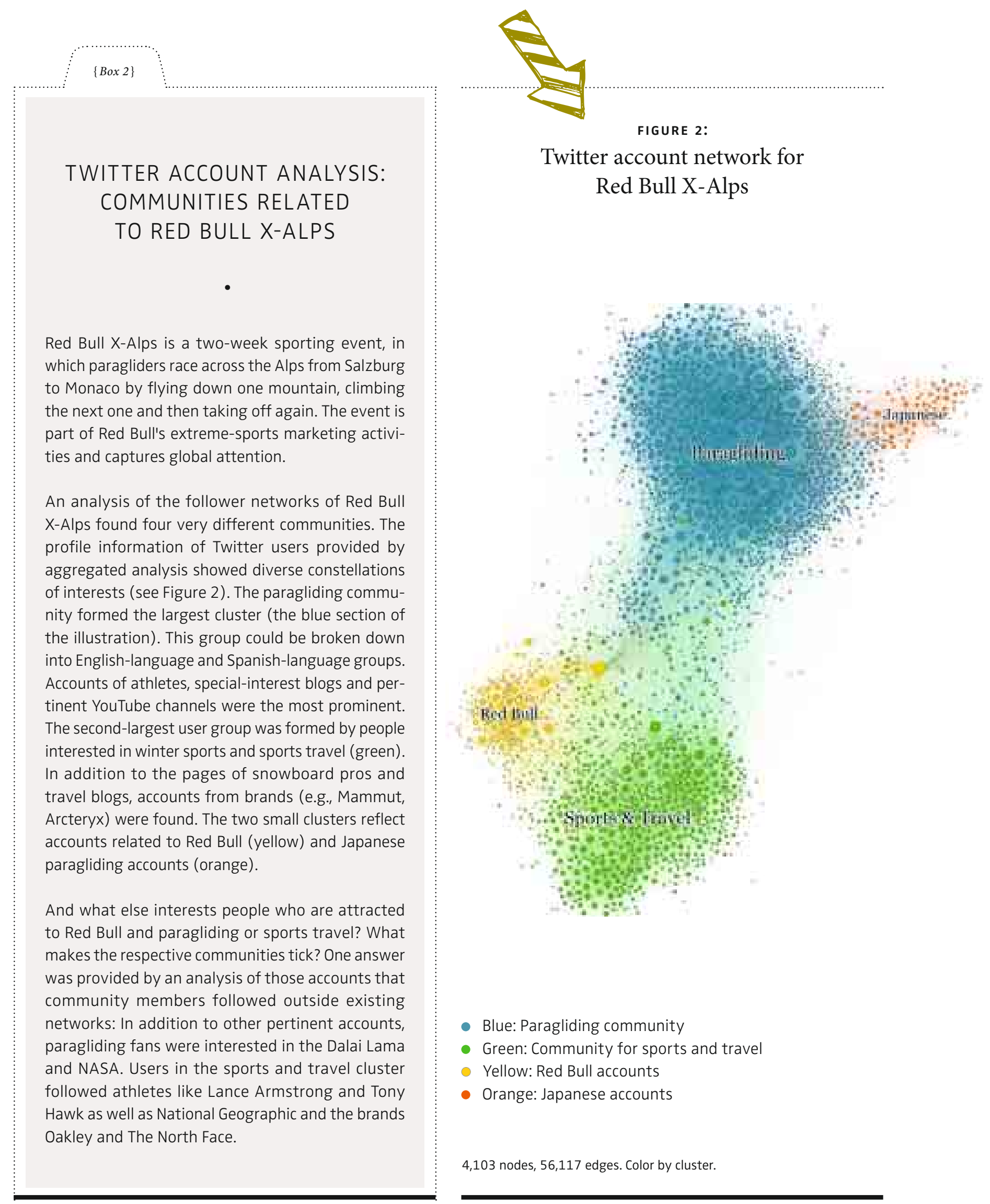

- Blue: Paragliding community

- Green: Community for sports and travel

- Yellow: Red Bull accounts

- Orange: Japanese accounts 
〉)

\section{Online communications}

represent social communications

in a much broader manner

than traditional mass media.

$\ll$
The analysis described here revealed much about the distribution of interests among users who follow a specific sporting event. The same methodological principles can also be applied to other identified constellations of users, including user lists generated from keyword-based searches in the Twitter stream. Particularly in the much-discussed area of social TV, account network analysis can deliver interesting insights into interest structures of users taking part in the conversation, and these insights make it possible to draw careful conclusions about segments of the entire audience.

\section{Online communications process as a mirror of society?}

/// The processes described here are methodologically timeconsuming, but can provide surprising insights that will be helpful in making strategic PR and marketing decisions: From a macro perspective, they show how online communications processes work. Both key players and dominant issues can be identified. Insights about the range of interests among diverse consumer groups and the structure of markets can be gained as well. The data must be interpreted with great care, and the social context of social media use must be considered.

Online communications represent social communications in a much broader manner than traditional mass media do because they encompass additional groups of players. But it must be remembered that the communications process monitored on the Internet primarily reflect those needs, wishes, problems, worries and interests that citizens and consumers share with one another in media-transmitted, public conversations. But these public communications processes are highly relevant to selection and purchasing decisions, and the methods of structural analysis of online communications described here serve as a valuable complement to market research.

I.

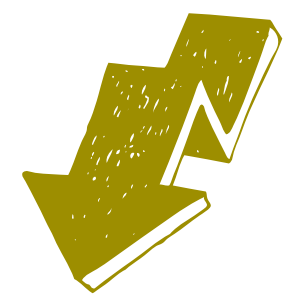

\section{FURTHER READING}

Maireder, A.; Schlögl, S. (in print):

"24 hours of an \#outcry: The networked publics of a socio-political debate",

European Journal of Communication. Advance online publication (September 2, 2014). doi: $10.1037 / \mathrm{a} 45 \mathrm{~d} 7867$.

Maireder A.; Ausserhofer J. (2013):

"Political Discourses on Twitter: Networking Topics, Object and People". In: Weller, K., Bruns, A., Burgess, J., Mahrt, M., and Puschmann, C. (Ed.). Twitter and Society, pp. $291-314$.

Bereitgestellt von | Vienna University Library Angemeldet Heruntergeladen am | 03.10.16 10:13 